Check for updates

Cite this: RSC Adv., 2018, 8, 25645

\title{
Localized incorporation of cesium ions to improve formamidinium lead iodide layers in perovskite solar cells $\dagger$
}

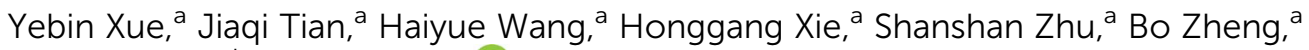 \\ Chunxiao $\mathrm{GaO}^{\mathrm{b}}$ and Xizhe Liu (D) *a
}

\begin{abstract}
For the perovskite solar cells with formamidinium lead iodide $\left(\mathrm{FAPbl}_{3}\right)$ as a light harvester, cesium ions $\left(\mathrm{Cs}^{+}\right)$ can be used to stabilize the perovskite crystal structure of $\mathrm{FAPb}_{3}$. However, the incorporation of $\mathrm{Cs}^{+}$ions usually reduces the grain size and degrades the crystallization of $\mathrm{FAPbl}_{3}$ layers, and this is harmful to the photovoltaic performance of solar cells. In this work, we incorporate $\mathrm{Cs}^{+}$ions into $\mathrm{FAPbl}_{3}$ layers using the interfacial doping method, which is different from the mixed solution doping method in previous reports. Elemental analysis indicates that $\mathrm{Cs}^{+}$dopants cannot be detected at the outer surfaces of perovskite layers, and the majority of $\mathrm{Cs}^{+}$dopants should be localized in the vicinity of $\mathrm{TiO}_{2} /$ perovskite interfaces, which is remarkably different from the distribution of $\mathrm{Cs}^{+}$dopants in the perovskite layers prepared using the mixed solution doping method. It is found that interfacial doping method can avoid the blue shift of the light absorption edge and can improve the crystallization of $\mathrm{FAPbl}_{3}$ layers. For the optimized conditions, $\mathrm{Cs}_{x} \mathrm{FA}_{1-x} \mathrm{Pbl}_{3}$ solar cells prepared using the interfacial doping method achieve a power conversion efficiency (PCE) of $17.1 \%$, which is better than the PCE of $\mathrm{Cs}_{x} \mathrm{FA}_{1-x} \mathrm{Pbl}_{3}$ devices prepared using the mixed solution doping method.
\end{abstract}

Received 3rd June 2018

Accepted 28th June 2018

DOI: $10.1039 / \mathrm{c} 8 \mathrm{ra04742a}$

rsc.li/rsc-advances

\section{Introduction}

Perovskite solar cells (PSCs) have become a research focus of photovoltaic devices for their solution processability and efficient solar-to-electric conversion. ${ }^{1-4}$ Their excellent photovoltaic performance comes from the application of organic lead halides as light harvesters, which have the perovskite structure of $\mathrm{ABX}_{3}{ }^{5,6}$ Although organic lead iodides based on formamidinium ions $\left(\mathrm{HC}\left(\mathrm{NH}_{2}\right)_{2}{ }^{+}, \mathrm{FA}^{+}\right)$are excellent light harvesting materials for photovoltaic devices, ${ }^{7-10}$ high quality $\alpha$-phase $\mathrm{FAPbI}_{3}$ layers are difficult to fabricate using solution deposition. $^{11,12}$ As a result of a large tolerance factor for $\alpha$-phase $\mathrm{FAPbI}_{3}$, the yellow $\delta$-phase with a hexagonal structure is the stable crystal structure for $\mathrm{FAPbI}_{3}$ at room temperature. To stabilize the $\alpha$-phase structure of $\mathrm{FAPbI}_{3}$, the $\mathrm{FA}^{+}$ions of $\mathrm{FAPbI}_{3}$ can be partially substituted with univalent cations with small sizes. ${ }^{13-15}$

Several reports indicate that partial substitution of $\mathrm{FA}^{+}$ions with cesium $\left(\mathrm{Cs}^{+}\right)$ions can eliminate the tension in $\mathrm{FAPbI}_{3}$ ${ }^{a}$ Institute of Atomic and Molecular Physics, Jilin Provincial Key Laboratory of Applied
Atomic and Molecular Spectroscopy, Jilin University, Changchun, 130012, China.
E-mail: liu_xizhe@jlu.edu.cn
${ }^{b}$ State Key Laboratory for Superhard Materials, Jilin University, Changchun, 130012,
China

$\dagger$ Electronic supplementary information (ESI) available. See DOI: 10.1039/c8ra04742a crystals, and this substantially improves the photovoltaic performance and stability of devices. ${ }^{16-19}$ Although $\mathrm{Cs}^{+}$doped $\mathrm{FAPbI}_{3}\left(\mathrm{Cs}_{x} \mathrm{FA}_{1-x} \mathrm{PbI}_{3}\right)$ exhibits some promising properties, the PCEs of devices are still relatively low compared to the state-ofthe-art records of PSCs. It is found that the incorporation of $\mathrm{Cs}^{+}$ ions intensely increases the density of crystal nuclei in the film formation process, which leads to a remarkable decrease in grain size in perovskite layers. ${ }^{20}$ The small grain size results in the enhancement of the recombination process in PSCs. ${ }^{21,22}$ On the other hand, the bandgap of $\mathrm{Cs}_{x} \mathrm{FA}_{1-x} \mathrm{PbI}_{3}$ increases with the increase in $\mathrm{Cs}^{+}$ions. ${ }^{16,17}$ Therefore, the incorporation of $\mathrm{Cs}^{+}$ions also leads to a blue shift in the light absorption edge for perovskite layers, which is harmful to the utilization of solar light.

$\mathrm{Cs}^{+}$ion doping is often implemented by incorporating CsI into the precursor solutions of $\mathrm{FAPbI}_{3} \cdot{ }^{16-19}$ In this doping method, $\mathrm{Cs}^{+}$ions tend to be dispersed in the entire film at all depths. Interfacial diffusion is another widely used method for incorporating dopants, and its doping profile is mainly localized in the vicinity of doping interfaces. ${ }^{23-25}$ This localized doping method can be adopted for preparing $\mathrm{Cs}^{+}$doped $\mathrm{FAPbI}_{3}$ layers, which are composed of a $\mathrm{Cs}^{+}$doped underlayer and an undoped capping layer. The undoped part of the perovskite layers tends to preserve the original bandgap of $\mathrm{FAPbI}_{3}$, which prevents the blue shift of light absorption by $\mathrm{Cs}^{+}$ion incorporation. It is also noted that this kind of doping profile likely generates a remarkable bandgap gradient in the vicinity of 
interfaces. The gradient structure of the bandgap can provide an additional driving force for the separation of photogenerated electrons and holes, and this is named the quasielectric field effect. ${ }^{26-28}$ Recent reports indicate that engineering the anion gradient at the outer surface of perovskite layers suppresses the recombination process of perovskite solar cells. ${ }^{29-31}$ Therefore, this localized doping method should be a promising way to promote the photovoltaic performance of $\mathrm{Cs}_{x} \mathrm{FA}_{1-x} \mathrm{PbI}_{3}$ solar cells.

In this work, we fabricated $\mathrm{Cs}_{x} \mathrm{FA}_{1-x} \mathrm{PbI}_{3}$ layers using the interfacial doping method as the light harvester of perovskite solar cells. By this localized $\mathrm{Cs}^{+}$doping, the crystallization was improved and the light absorption range was preserved for these perovskite layers. After optimizing the quantity of dopants, the recombination process of PSCs was suppressed and the power conversion efficiency (PCE) can be promoted.

\section{Experimental}

Firstly, FTO glass was etched using a $1064 \mathrm{~nm}$ laser and it was ultrasonically cleaned using acetone and ethanol. Then, a $30 \mathrm{~nm} \mathrm{\textrm {TiO } _ { 2 }}$ blocking layer was deposited on the cleaned FTO using spray pyrolysis of $2.0 \quad \mathrm{~mL} \quad 0.05 \quad \mathrm{M} \quad \mathrm{Ti}(\mathrm{OPr})_{2^{-}}$ (acetylacetonate) ${ }_{2}$ solution using oxygen as the carrying gas at $450{ }^{\circ} \mathrm{C}$. Then a mesoporous $\mathrm{TiO}_{2}$ film was deposited using spincoating with an ethanol diluted $\mathrm{TiO}_{2}$ paste (18NRT, Dyesol) solution at $5000 \mathrm{rpm}$ for $30 \mathrm{~s}$. The mass ratio of original $\mathrm{TiO}_{2}$ paste to ethanol is $1: 6$. These samples were dried and sintered at $80{ }^{\circ} \mathrm{C}$ for $30 \mathrm{~min}, 100{ }^{\circ} \mathrm{C}$ for $30 \mathrm{~min}, 350{ }^{\circ} \mathrm{C}$ for $30 \mathrm{~min}$, and $500{ }^{\circ} \mathrm{C}$ for $30 \mathrm{~min}$ sequentially. Then CsI doping layers were deposited using spin-coating at $4000 \mathrm{rpm}$ for $30 \mathrm{~s}$ with 50, 100, and $200 \mathrm{mg} \mathrm{mL}^{-1}$ CsI in $N, N$-dimethylformamide (DMF) solutions, which are labelled as CsI50, CsI100 and CsI200 respectively. Undoped samples without CsI doping layers were also prepared as the reference. For preparing formamidinium perovskite layers, $\mathrm{PbI}_{2}$ films were deposited on the samples using spin-coating with $462 \mathrm{mg} \mathrm{mL}^{-1} \mathrm{PbI}_{2}$ in DMF solution at $4000 \mathrm{rpm}$ for $30 \mathrm{~s}$. After preheating at $160^{\circ} \mathrm{C}$ for $10 \mathrm{~min}$ on a hot plate, $60 \mu \mathrm{L} 50 \mathrm{mg} \mathrm{mL}^{-1}$ FAI in isopropanol solution was sprayed on the top of the $\mathrm{PbI}_{2}$ film using a nitrogen gas atomizing spray nozzle at $160^{\circ} \mathrm{C}$. After the interface reaction process, the film was washed with isopropanol and annealed at $160{ }^{\circ} \mathrm{C}$ for another $10 \mathrm{~min}$. We also fabricated $\mathrm{Cs}^{+}$doped $\mathrm{FAPbI}_{3}$ layers by directly spin-coating a mixed solution of $0.1 \mathrm{M}$ CsI and $1.0 \mathrm{M}$ $\mathrm{PbI}_{2}$ in DMF, which acts as the precursor layer in the mixed solution doping method..$^{19}$ When cooled to room temperature, hole transport material layers were prepared using spin-coating of a solution containing $72.3 \mathrm{mg}$ spiro-MeOTAD, $28.5 \mu \mathrm{L}$ 4-tertbutylpyridine and $\quad 18.5 \quad \mu \mathrm{L} \quad$ lithium bis(trifluoromethanesulfonyl)imide solution $\left(520 \mathrm{mg} \mathrm{mL}^{-1}\right.$ in acetonitrile) in $1 \mathrm{~mL}$ of chlorobenzene as the solvent at $4000 \mathrm{rpm}$ for $30 \mathrm{~s}$. After being aged in a brown desiccator for 12 hours, $\mathrm{Au}$ electrodes were deposited using vacuum thermal evaporation.

Scanning electron microscopy (SEM) was investigated using a FEI-MAGELLAN 400 scanning electron microscope. X-ray diffraction (XRD) patterns were obtained using a Rigaku D/ max-2550 X-ray diffractometer. The UV-vis absorption spectra were recorded with a L5S UV-vis spectrophotometer in the 500$900 \mathrm{~nm}$ wavelength range. Photocurrent density-photovoltage characteristics were recorded from $1.10 \mathrm{~V}$ to $0 \mathrm{~V}$ using a CHI660 electrochemical workstation. The active area of the solar cells is $0.16 \mathrm{~cm}^{2}$, which is defined by a mask. The AM1.5 illumination was provided by a $3 \mathrm{~A}$ class solar simulator (UHE-16, ScienceTech Inc.), which was calibrated to one sun by a KG5-filtered Si reference solar cell (certificated by VLSI Standards Inc., traceable to the National Renewable Energy Laboratory). Photoluminescence (PL) spectra were detected using a CCD detector (PIXIS256BR, Princeton Instruments Inc.), and the excitation wavelength was $532 \mathrm{~nm}$, provided by a low-noise solid-state laser (MLL-III-532). Impedance spectra were measured under constant illumination conditions over a frequency range from 1 MHz to $1 \mathrm{~Hz}$ using a CHI660 electrochemical workstation. The constant illumination was provided by a white LED lamp array. Inductively coupled plasma (ICP) analysis was investigated using an Agilent 7500a inductively coupled plasma source mass spectrometer. X-ray photoelectron spectroscopy (XPS) was performed using an X-ray photoelectron spectrometer (Thermo Scientific Escalab 250Xi).

\section{Results and discussion}

As shown in Fig. 1a, the $\mathrm{PbI}_{2}$ films without CsI doping layers are composed of irregular nanoparticles. However, the morphology of $\mathrm{PbI}_{2}$ films change remarkably by inserting CsI doping layers between $\mathrm{TiO}_{2}$ layers and $\mathrm{PbI}_{2}$ layers. For the doping layers produced using the $50 \mathrm{mg} \mathrm{mL}^{-1}$ CsI solution (CsI50 layers), $\mathrm{PbI}_{2}$ films are composed of nanorod-like grains. By increasing the concentration of CsI solutions to $100 \mathrm{mg} \mathrm{mL}^{-1}$ and $200 \mathrm{mg}$ $\mathrm{mL}^{-1}$ (CsI100 and CsI200 layers), pinhole defects emerge and increase in the $\mathrm{PbI}_{2}$ layers (Fig. 1c and d). These results indicate that CsI doping layers can modify the morphology of $\mathrm{PbI}_{2}$ layers. As perovskite layers are prepared by the reaction between $\mathrm{PbI}_{2}$ layers and the FAI precursor, the morphology of $\mathrm{PbI}_{2}$ layers also affects the formation of perovskite layers. Fig. 1e shows the XRD patterns of $\mathrm{PbI}_{2}$ films without and with different CsI doping layers. CsI50 doping layers lead to a moderate reduction in the intensity of the $\mathrm{PbI}_{2}$ diffraction peak at $12.8^{\circ}$. After further increasing the quantity of CsI dopants (CsI100 and CsI200), the intensity of the $\mathrm{PbI}_{2}$ diffraction peaks decrease remarkably. This result indicates that the incorporation of CsI doping layers can decrease the crystallization of $\mathrm{PbI}_{2}$ layers. Low crystallization of $\mathrm{PbI}_{2}$ layers favours the accessibility of organic ammonium iodide to inner lead sites, and this can be beneficial to the crystal growth of perovskite layers. ${ }^{32,33}$

Fig. 2 shows the morphology of perovskite layers from different $\mathrm{PbI}_{2}$ layers using SEM measurements. The perovskite layer produced from the undoped $\mathrm{PbI}_{2}$ layer is composed of small grains with the average size of $150 \mathrm{~nm}$ (Fig. 2a). For the $\mathrm{PbI}_{2}$ layers with CsI50 doping layers, the average grain size of perovskite layers remarkably increases to $420 \mathrm{~nm}$ (Fig. 2b), and the perovskite layers retain a compact structure. It means that $\mathrm{PbI}_{2}$ layers with nanorod like grains facilitate the growth of perovskite grains, which is beneficial for producing high quality perovskite layers. After further increasing the quantity of the CsI 

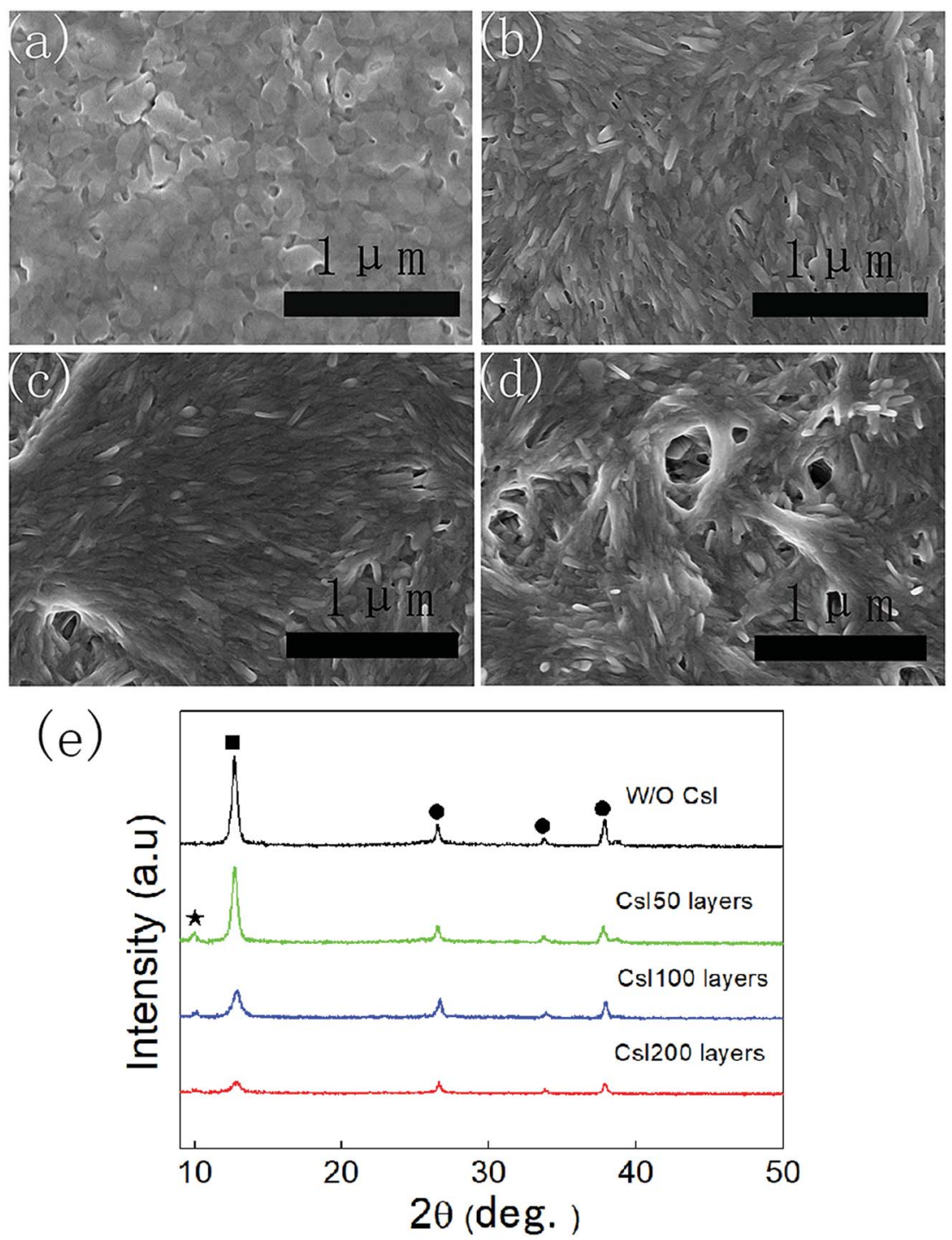

Fig. 1 Top-view SEM images of $\mathrm{Pbl}_{2}$ layers without (a) and with CsI50 (b), CsI100 (c), CsI200 (d) doping layers, and (e) X-ray diffraction patterns of $\mathrm{Pbl}_{2}$ layers without and with different $\mathrm{Csl}$ doping layers, where the diffraction peaks of $\mathrm{FTO}, \mathrm{Pbl}_{2}$ and $\delta$ - $\mathrm{CsPb} \mathrm{P}_{3}$ are labelled with solid circles, solid squares and solid asterisks, respectively.

dopant, the average grain size of formamidinium perovskite layers continuously increases to $450 \mathrm{~nm}$ (Fig. 2c) and $500 \mathrm{~nm}$ (Fig. 2d), while pinhole defects emerge in the perovskite layers. These pinholes are likely related to the holes in $\mathrm{PbI}_{2}$ layers in Fig. $1 \mathrm{c}$ and d. Although small holes in $\mathrm{PbI}_{2}$ layers can be eliminated by the volume expansion in the formation of perovskite layers, big holes still lead to pinhole defects in perovskite layers. These pinhole defects are usually harmful to the device performance.

The XRD patterns of these four different perovskite layers are shown in Fig. 3a, and all of the XRD diffraction peaks can be assigned to $\mathrm{Cs}_{x} \mathrm{FA}_{1-x} \mathrm{PbI}_{3}$ with $\alpha$-phase and FTO substrates. ${ }^{16,17}$ It means that formamidinium perovskite layers with pure $\alpha$ phases can be prepared using the two step method. Moreover, the full width of half maximum (FWHM) of (110) diffraction peaks in these formamidinium perovskite layers is extracted from Fig. 3a, and these are summarized in Fig. 3b. The FWHM of formamidinium perovskite layers without CsI doping is $0.301^{\circ}$. By introducing CsI50 doping layers, the FWHM of formamidinium perovskite layers decreases to $0.241^{\circ}$. When the quantity of CsI dopants further increases (CsI100 and CsI200), the FWHM of formamidinium perovskite layers moderately increase to $0.260^{\circ}$ and $0.272^{\circ}$, respectively. The broadening of XRD peaks usually comes from the low quality of crystallization, and consequently a small FWHM is related to the high quality of perovskite layers. Therefore, the optimized doping layer of CsI50 promotes the crystallization of formamidinium perovskite layers. In previous reports, $\mathrm{Cs}_{x} \mathrm{FA}_{1-x} \mathrm{PbI}_{3}$ layers are usually obtained by directly adding CsI dopants into the precursor solution, and CsI dopants usually lead to a decrease in grain size and crystallization in $\mathrm{FAPbI}_{3}$ layers. In contrast, these interfacial doping layers can remarkably increase the grain size and crystallization of $\mathrm{FAPbI}_{3}$ layers, which should be a promising doping method for $\mathrm{Cs}_{x} \mathrm{FA}_{1-x} \mathrm{PbI}_{3}$ solar cells. 


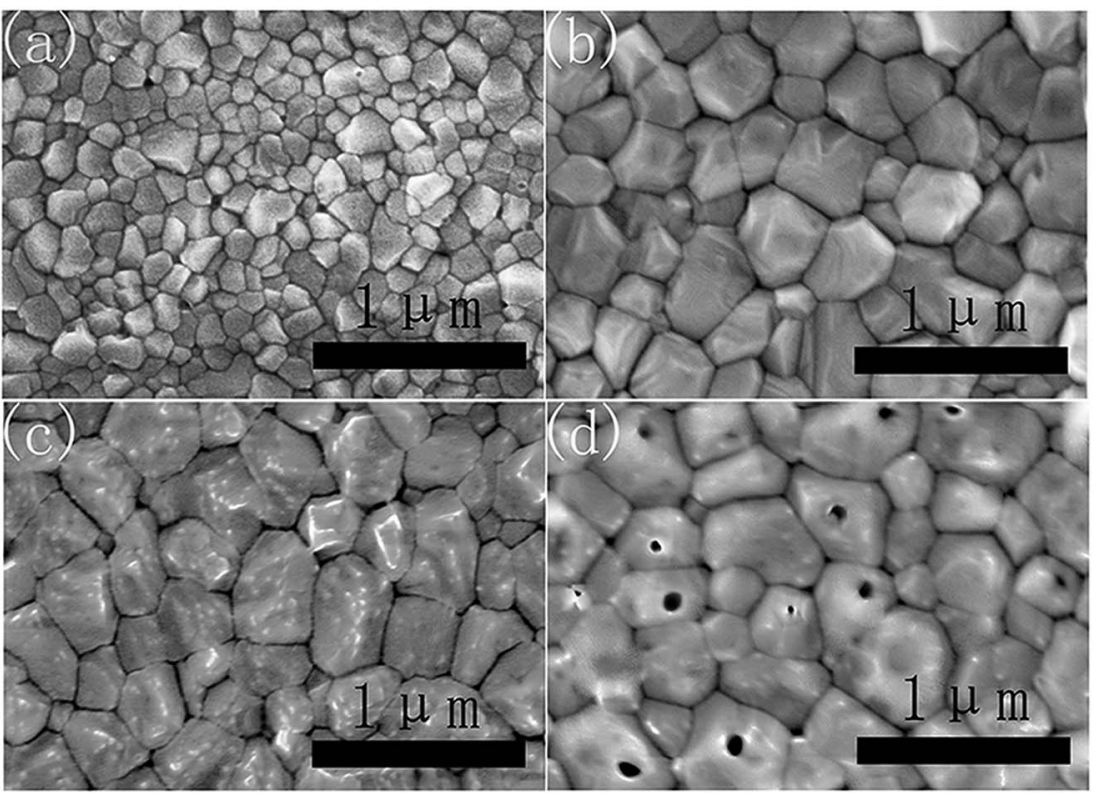

Fig. 2 Top-view SEM images of perovskite layers without (a) and with CsI50 (b), CsI100 (c), and CsI200 (d) doping layers.

(a)

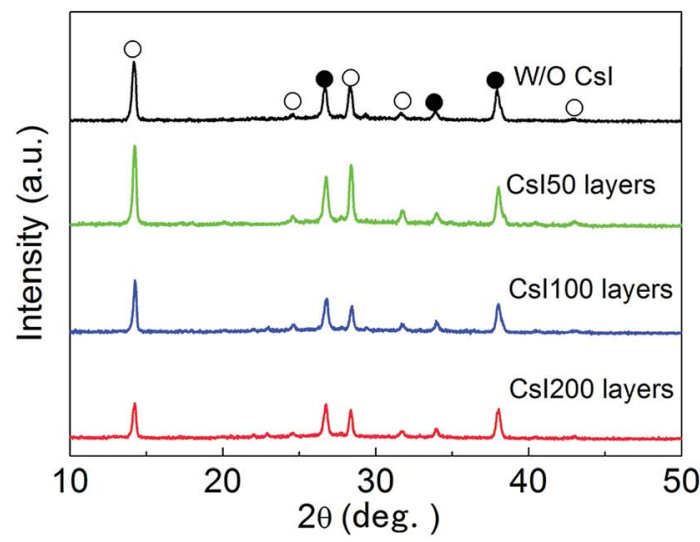

(b)

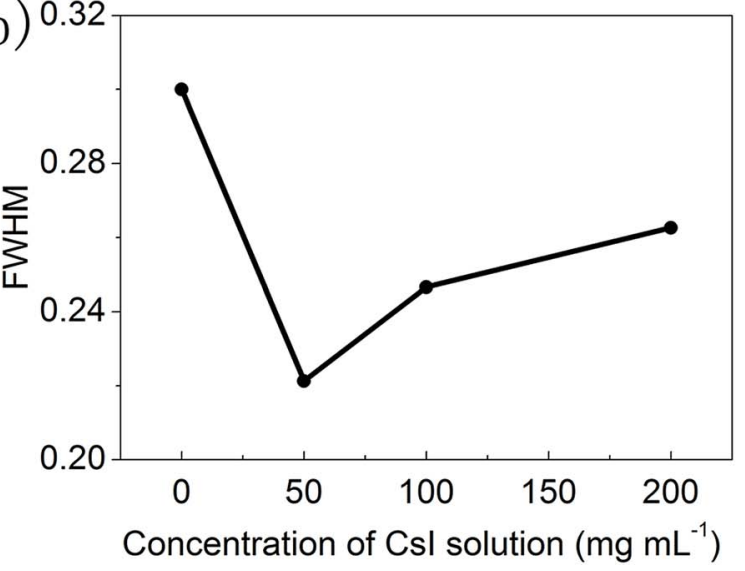

Fig. 3 (a) X-ray diffraction patterns of perovskite layers without and with different Csl doping layers, and (b) FWHM of (110) diffraction peaks. Diffraction peaks of FTO and perovskite are labelled with solid circles and open circles, respectively.
XRD measurements were also performed to analyse the formation of $\mathrm{Cs}_{x} \mathrm{FA}_{1-x} \mathrm{PbI}_{3}$ layers prepared using the interfacial doping method (Fig. 4a). After the spincoating of $1.0 \mathrm{M} \mathrm{PbI}_{2}$ solution on CsI doping layers, the diffraction peaks of CsI $\left(27.9^{\circ}, 39.8^{\circ}\right)$ disappear, while the diffraction peak of $\mathrm{PbI}_{2}$ $\left(12.8^{\circ}\right)$ and another diffraction peak at $10.01^{\circ}$ appear. These new diffraction peaks can be assigned to the formation of $\delta$ $\mathrm{CsPbI}_{3} \cdot{ }^{34,35}$ This means that an interdiffusion reaction between CsI layers and $\mathrm{PbI}_{2}$ layers has taken place. As the quantity of CsI is much smaller than that of $\mathrm{PbI}_{2}, \delta-\mathrm{CsPbI}_{3}$ is likely located in the vicinity of doping interfaces. After reacting with the FAI precursor, the diffraction peaks of $\mathrm{PbI}_{2}$ and $\delta-\mathrm{CsPI}_{3}$ are eliminated and the diffraction peaks of the black $\alpha$-phase perovskite materials emerged. Therefore, the precursor layers react with FAI completely and $\mathrm{Cs}_{x} \mathrm{FA}_{1-x} \mathrm{PbI}_{3}$ layers with a pure $\alpha$-phase structure can be obtained. It is also noted that the diffraction peaks of $\mathrm{PbI}_{2}$ and CsI can be found in the $\mathrm{PbI}_{2}$ layers prepared using the mixed solution method and the diffraction peaks of $\delta$ $\mathrm{CsPbI}_{3}$ are not observed (Fig. $\mathrm{S} 1 \dagger$ ). The relatively homogenous distribution of CsI in $\mathrm{PbI}_{2}$ layers prepared using the mixed solution method leads to a small $\mathrm{CsI} / \mathrm{PbI}_{2}$ ratio, which is far from the stoichiometric ratio required to form $\delta-\mathrm{CsPb}_{3}$. However, the CsI dopant mainly localizes in the vicinity of doping interfaces for the interfacial doping method, which satisfies the stoichiometric ratio to form $\delta-\mathrm{CsPbI}_{3}$.

To further clarify the features of these $\mathrm{Cs}_{x} \mathrm{FA}_{1-x} \mathrm{PbI}_{3}$ layers, elemental analysis was performed on the perovskite layers prepared using the interfacial doping method, and the $\mathrm{Cs}_{x^{-}}$ $\mathrm{FA}_{1-x} \mathrm{PbI}_{3}$ layers prepared using the mixed solution method were employed as the reference. Fig. $4 \mathrm{~b}$ shows the X-ray photoelectron spectra (XPS) of $\mathrm{Cs}_{x} \mathrm{FA}_{1-x} \mathrm{PbI}_{3}$ layers. For the sample prepared using the mixed solution method, clear peaks due to $\mathrm{Pb}$ and $\mathrm{Cs}$ elements can be distinguished. On the contrary, the XPS peak due to the Cs element cannot be detected 

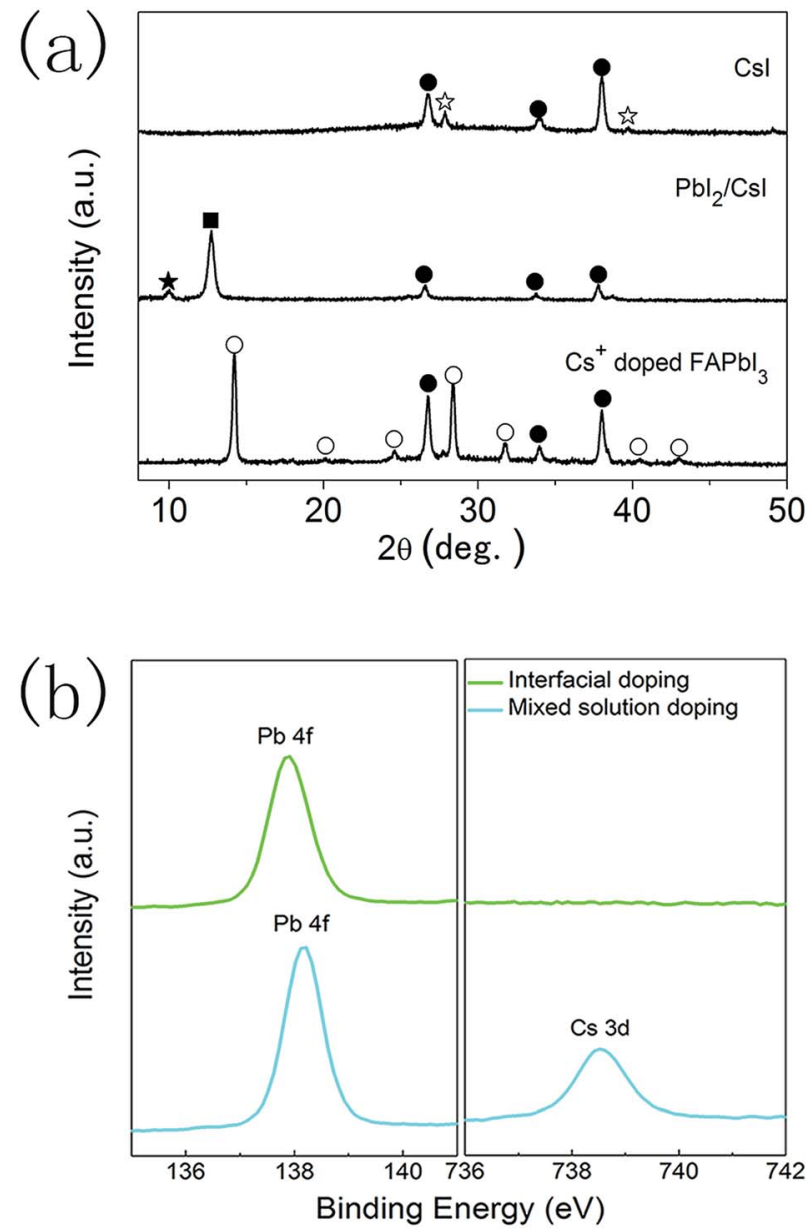

Fig. 4 (a) X-ray diffraction patterns for the deposition process of the interfacial doping method, where diffraction peaks of FTO, Csl, $\mathrm{Pbl}_{2}, \delta$ $\mathrm{CsPbl}_{3}$ and $\alpha-\mathrm{FAPbl}_{3}$ are labelled with solid circles, open asterisks, solid squares, solid asterisks and open circles, respectively. (b) XPS spectra of perovskite layers prepared using the interfacial doping and mixed solution doping methods.

for the $\mathrm{Cs}_{x} \mathrm{FA}_{1-x} \mathrm{PbI}_{3}$ layers prepared using the interfacial doping method, which indicates a very low concentration of the Cs element at the outer surfaces of perovskite layers. ICP measurements indicate that the global doping ratio of $\mathrm{Cs}^{+}$ions is $15.6 \%$ for the perovskite layers with CsI50 doping layers, which is far from the undetectable limit of the Cs element. As XPS spectra represent the surface properties, the remarkably different $\mathrm{Cs}^{+}$concentration at the outer surfaces of perovskite layers confirms the different $\mathrm{Cs}^{+}$concentration profiles at different depths by these two doping methods. The undetectable XPS signal of the Cs element implies that the majority of $\mathrm{Cs}^{+}$ions are located in the vicinity of $\mathrm{TiO}_{2} /$ perovskite interfaces for the interfacial doping method. The binding energies of $\mathrm{Pb} 4 \mathrm{f}$ peaks are $137.9 \mathrm{eV}$ and $138.2 \mathrm{eV}$ for the perovskite layers prepared using the interfacial doping method and the mixed solution method, respectively (Fig. 4b). The cesium dopant can lead to an increase in the binding energy of the $\mathrm{Pb} 4 \mathrm{f}$ peaks, and this is related to the change in the chemical bonding nature by the shrinkage of lattice parameters. ${ }^{16,17}$ Therefore, the relatively low binding energy of $\mathrm{Pb} 4 \mathrm{f}$ peaks for the sample prepared using the interfacial doping method is in accordance with the low $\mathrm{Cs}^{+}$ concentration at the outer surfaces of perovskite layers.

To explore the effect of this localized $\mathrm{Cs}^{+}$doping on the device performance, a series of PSCs are fabricated with different CsI doping layers. Fig. 5a shows the photocurrent density-photovoltage curves of the best-performing devices and their photovoltaic parameters are summarized in Table S1. $\dagger$ The device without a CsI doping layer has a PCE of $13.4 \%$ with an open circuit voltage $\left(V_{\mathrm{oc}}\right)$ of $1.01 \mathrm{~V}$, a short-circuit current density $\left(J_{\mathrm{sc}}\right)$ of $20.1 \mathrm{~mA} \mathrm{~cm} \mathrm{~cm}^{-2}$, and a fill-factor of 0.66 . After inserting a CsI doping layer by spincoating a $50 \mathrm{mg} \mathrm{mL}$ solution, the PCE of the device is promoted to $17.1 \%$, which comes from the simultaneous increase in $J_{\mathrm{sc}}\left(23.0 \mathrm{~mA} \mathrm{~cm}{ }^{-2}\right), V_{\mathrm{oc}}$ $(1.05 \mathrm{~V})$ and the fill-factor $(0.71)$. This result indicates that a CsI doping layer can improve the performance of formamidinium perovskite solar cells, which can be related to the improvement in crystallization for perovskite layers (Fig. 2 and 3). However, further increasing the quantity of CsI dopant diminishes the device performance to $12.7 \%$ and $9.8 \%$ for the CsI100 and CsI200 doping layers, respectively. It is in accordance with the emergence of pinhole defects and degradation of crystallization in the perovskite layers by increasing the CsI quantity (Fig. 2 and 3). To evaluate the reproducibility, we performed
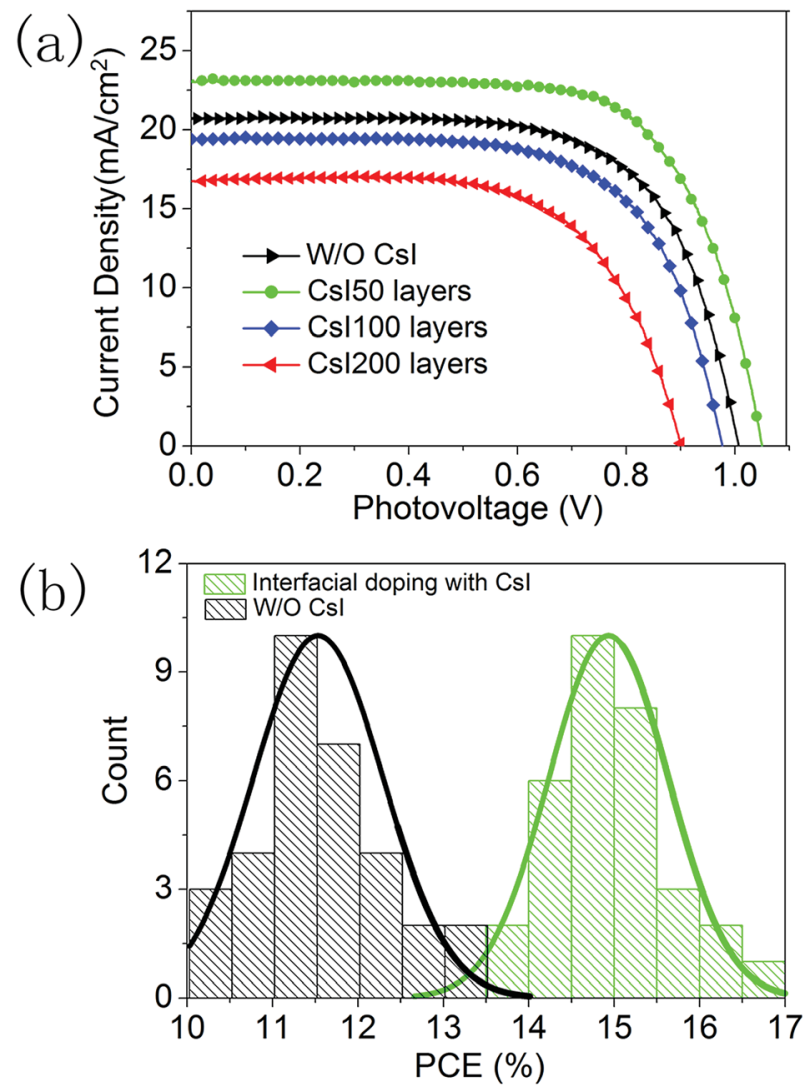

Fig. 5 (a) J-V curves of devices without and with different Csl doping layers under one Sun illumination, and (b) statistical analysis of PCEs for 32 devices without and with CsI50 doping layers under one Sun illumination. 
a statistical analysis of 32 devices for undoped devices and CsI50 layers doped devices in Fig. 5b. For the devices with CsI50 doping layers, the PCEs of devices are distributed in the range from $13.5 \%$ to $17.1 \%$ with an average efficiency of about $14.9 \%$. In contrast, the average PCE of undoped devices is located at $11.5 \%$. This result confirms that CsI50 doped layers promote the performance of $\mathrm{Cs}_{x} \mathrm{FA}_{1-x} \mathrm{PbI}_{3}$ solar cells.

Fig. 6a shows the incident photon-to-electron conversion efficiency (IPCE) spectra of devices with different CsI doping layers. Although $\mathrm{Cs}^{+}$ions have usually increased the bandgap of $\mathrm{FAPbI}_{3}$ in previous reports, these CsI doping layers do not lead to the blue shift in the onset wavelength (at about $840 \mathrm{~nm}$ ). This means that these $\mathrm{Cs}_{x} \mathrm{FA}_{1-x} \mathrm{PbI}_{3}$ layers prepared using the interfacial doping method are different from the ones prepared using mixed solution doping, and interfacial doping is beneficial to preserve the broad light response range of $\mathrm{FAPbI}_{3}$. In Fig. 6a, the difference of these IPCE spectra mainly comes from the IPCE values. CsI50 doping layers can lead to the increase in IPCE values, while further increasing of the CsI quantity results in the decrease of IPCE values. As IPCE spectra are directly related with the $J_{\mathrm{sc}}$ of solar cells, the tendency of IPCE values is in accordance with that of $J_{\mathrm{sc}}$ in Fig. 5a. The photovoltaic
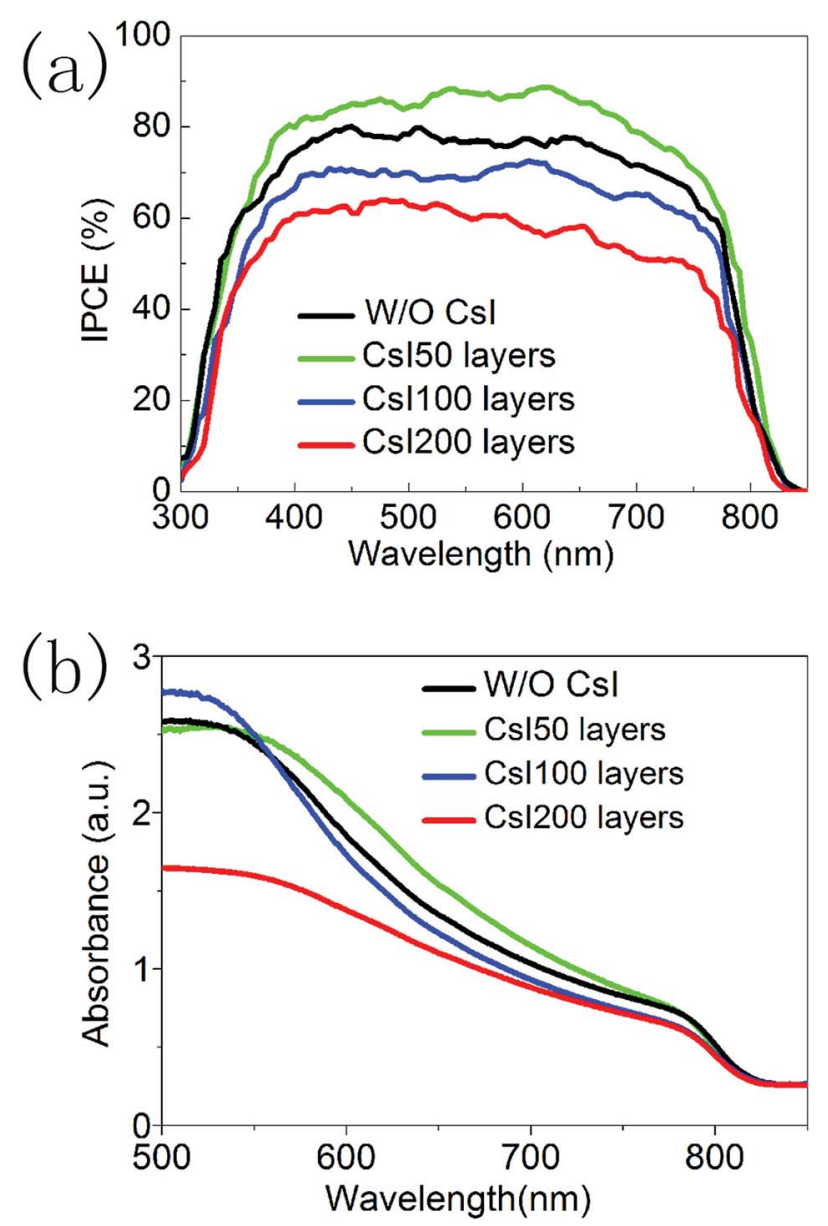

Fig. 6 (a) IPCE spectra of devices without and with different CSI doping layers. (b) Absorption spectra of perovskite layers without and with different $\mathrm{Csl}$ doping layers. performance and IPCE spectra of these devices can be further analysed by the light absorption process and the recombination-transport process.

Fig. 6b shows the light absorption spectra of perovskite layers with different CsI doping layers. All of these samples have similar absorption edges at about $840 \mathrm{~nm}$. In the interfacial doping process, $\mathrm{Cs}^{+}$ions tend to locate in the vicinity of doping interfaces, and undoped capping layers of pure $\mathrm{FAPbI}_{3}$ exist at the outer surface. Thus the light absorption range of $\mathrm{Cs}_{x^{-}}$ $\mathrm{FA}_{1-x} \mathrm{PbI}_{3}$ layers can be preserved. It is noted that CsI50 doping layers lead to an increase in the absorption coefficient in a wavelength range of 550-750 $\mathrm{nm}$. However, further increasing the quantity of CsI dopant results in a decrease in absorption. This tendency is similar to the absorption of $\mathrm{Cs}_{x} \mathrm{FA}_{1-x} \mathrm{PbI}_{3}$ layers prepared using the mixed solution method. ${ }^{\mathbf{1 6 , 1 7}}$ The improvement of light absorption can increase the generation of photoelectrons in the conduction band of perovskite layers, and this is beneficial for the output of photocurrent.

To investigate the recombination-transport process, we performed impedance measurements for these four devices with different CsI doping layers. The Nyquist plots are shown in Fig. 7a, and they can be distinguished into two impedance arcs. The impedance arc at the low frequency comes from the recombination process in perovskite solar cells, and the impedance arc at the high frequency is usually related to the charge transfer process at interfaces. ${ }^{36,37}$ After fitting the impedance spectra with the equivalent circuit (Fig. S2 $\dagger$ ), the recombination resistance and charge transfer resistance can be extracted. Fig. 7b shows the recombination resistance of devices with different CsI doping layers under a series of applied potentials. At small applied potentials, the recombination resistance can be increased by inserting CsI50 doping layers, and this reflects the decrease in recombination velocity. It is likely related to the improvement in crystallization by inserting CsI50 doping layers. A low recombination velocity is beneficial for the transport process of photo-generated electrons, which is in accordance with the trend of the photocurrent in Fig. 5a. Further increasing the quantity of the CsI dopant (CsI100 and CsI200) leads to the decrease in the recombination resistance continuously. By increasing the bias potential, the recombination resistance decreases continuously, but its trend does not change. At high applied potentials, the relatively large recombination resistance leads to a high density of electrons in conduction bands, which is beneficial for promoting $V_{\text {oc }}$ of devices. Fig. 7c shows the charge transfer resistances at different applied potentials. The charge transfer resistance decreases when inserting CsI50 doping layers, but it increases after further increasing the quantity of the CsI dopant (CsI100 and CsI200). A low charge transfer resistance enhances the electron transfer at the $\mathrm{TiO}_{2} /$ perovskite interfaces, which is beneficial for the charge collection process.

We further compared the photovoltaic performance of devices prepared using the interfacial doping method and the mixed solution doping method, and 32 devices were fabricated for the statistical analysis. The CsI50 layers are used in the interfacial doping method, while $10 \mathrm{~mol} \%$ CsI dopant is employed for the mixed solution method as in the optimization 


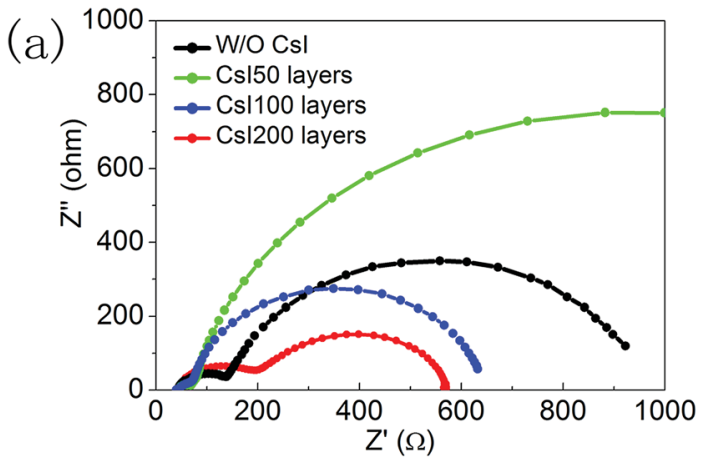

(b)
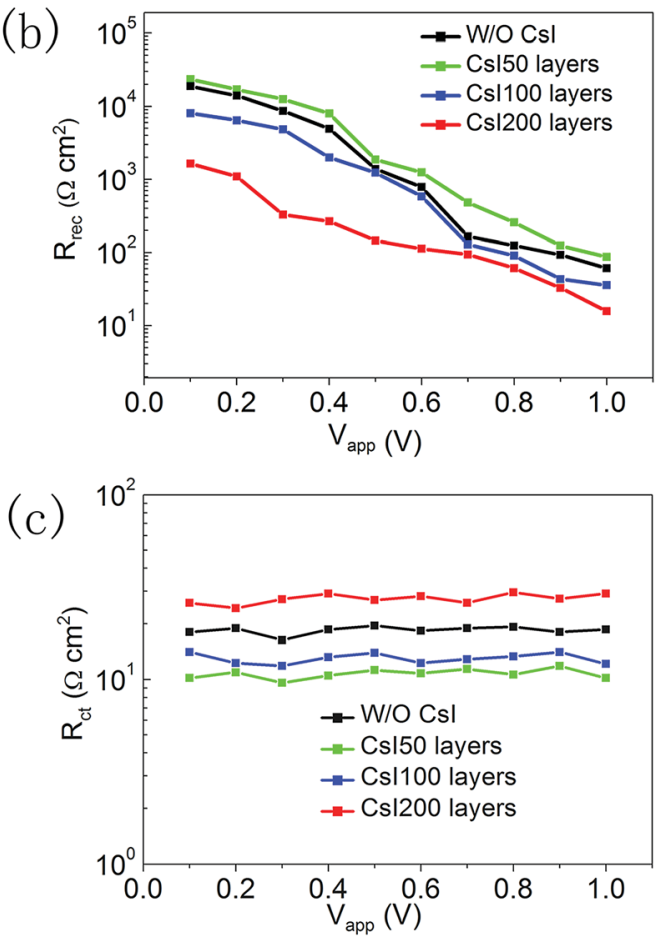

Fig. 7 (a) Nyquist plots of devices without and with different CsI doping layers at a bias potential of $0.8 \mathrm{~V}$, (b) the recombination resistance and (c) charge transfer resistance of devices under different applied potentials.

conditions of previous reports. ${ }^{18,19}$ In Fig. 8a, the best PCE of $17.1 \%$ with a $J_{\text {sc }}$ of $23.0 \mathrm{~mA} \mathrm{~cm}{ }^{-2}$, a $V_{\text {oc }}$ of $1.05 \mathrm{~V}$ and a fill-factor of 0.71 is achieved for the interfacial doping method, while the best performing device prepared using the mixed solution method gives a PCE of $15.0 \%$ with a $J_{\mathrm{sc}}$ of $21.8 \mathrm{~mA} \mathrm{~cm}^{-2}$, a $V_{\mathrm{oc}}$ of $1.03 \mathrm{~V}$ and a fill-factor of 0.67. As shown in Fig. 4a and Fig. S1, $\dagger$ both doping methods can produce $\mathrm{Cs}_{x} \mathrm{FA}_{1-x} \mathrm{PbI}_{3}$ layers with pure $\alpha$-phase structures. However, the cutoff wavelength of IPCE spectra is $840 \mathrm{~nm}$ for the device prepared using the interfacial doping method, while it is $825 \mathrm{~nm}$ for the device prepared using the mixed solution doping method (Fig. S3†). The relatively broad wavelength range of light responses can be related to the avoidance of the blue shift for the absorption edge of the material prepared using the interfacial doping method. It is beneficial for the utilization of solar illumination, which can lead to the relatively high photocurrent density of the material prepared using the interfacial doping method. Fig. $\mathrm{S} 4 \uparrow$ shows

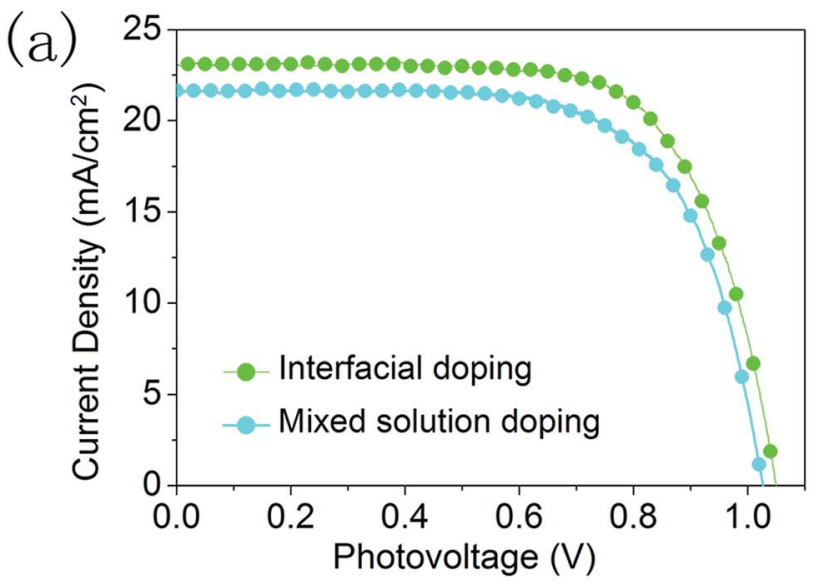

(b)

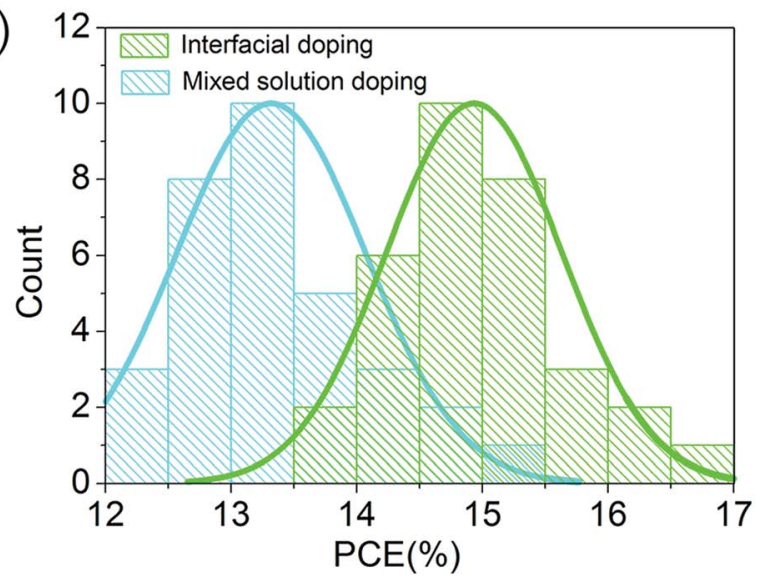

Fig. 8 (a) J-V curves of devices prepared using mixed solution doping and interfacial doping under one sun illumination, and (b) statistical analysis of PCEs for 32 devices prepared using mixed solution doping and interfacial doping under one sun illumination.

the surface morphology of these $\mathrm{Cs}_{x} \mathrm{FA}_{1-x} \mathrm{PbI}_{3}$ layers prepared using two different doping methods. The interfacial doping method leads to an average grain size of $420 \mathrm{~nm}$, while the mixed solution method gives an average grain size of $330 \mathrm{~nm}$. As a large size of perovskite grains reduces the scattering of charge carriers at the grain boundaries, the charge collection process can be improved by the interfacial doping method. Fig. $8 \mathrm{~b}$ is the statistical analysis of PCEs for 32 devices prepared using these two kinds of doping methods. The devices based on interfacial doping and mixed solution doping achieve average PCEs of $14.9 \%$ and $13.4 \%$ respectively, which confirms the advantages of the interfacial doping method for $\mathrm{Cs}_{x} \mathrm{FA}_{1-x} \mathrm{PbI}_{3}$ solar cells.

\section{Conclusions}

In summary, we developed an interfacial doping method for producing $\mathrm{Cs}^{+}$doped $\mathrm{FAPbI}_{3}$ layers as the light harvester of perovskite solar cells. In contrast to the previous mixed solution method, the concentration of cesium dopants is very low at the outer surfaces of perovskite layers, and the majority of cesium dopants should be located in the vicinity of $\mathrm{TiO}_{2} /$ perovskite interfaces. It is found that CsI doping layers affect the 
morphology of $\mathrm{PbI}_{2}$ layers, which subsequently improves the crystallization and morphology of $\mathrm{Cs}_{x} \mathrm{FA}_{1-x} \mathrm{PbI}_{3}$ layers. For the optimized CsI doping layers, the light absorption process and charge collection process can be improved, and the PCE of devices can be increased from $13.4 \%$ to $17.1 \%$. Light absorption spectra show that the interfacial doping method can avoid the blue shift of the absorption edge, and this is beneficial for the utilization of solar energy. Furthermore, the interfacial doping method leads to a better performance than the previous mixed solution method for $\mathrm{Cs}_{x} \mathrm{FA}_{1-x} \mathrm{PbI}_{3}$ solar cells.

\section{Conflicts of interest}

There are no conflicts to declare.

\section{Acknowledgements}

This work was partially supported by the National Natural Science Foundation of China (Grant No. 51772125, 51273079 and 11674404) and the Jilin Provincial Research Foundation for Basic Research (Grant No. 20180101214JC).

\section{Notes and references}

1 A. Kojima, K. Teshima, Y. Shirai and T. Miyasaka, J. Am. Chem. Soc., 2009, 131, 6050-6051.

2 J. Im, C. Lee, J. Lee, S. Park and N. Park, Nanoscale, 2011, 3, 4088-4093.

3 H. Kim, C. Lee, J. Im, K. Lee, T. Moehl, A. Marchioro, S. Moon, R. Humphry-Baker, J. Yum, J. Moser, M. Grätzel and N. Park, Sci. Rep., 2012, 2, 591.

4 M. Lee, J. Teushcer, T. Miyasaka, T. Murakami and H. Snaith, Science, 2012, 338, 643-647.

5 C. Stoumpos, C. Malliakas and M. Kanatzidis, Inorg. Chem., 2013, 52, 9019-9038.

6 W. Zhang, G. Eperon and H. Snaith, Nat. Energy, 2016, 1, 16048.

7 W. Yang, J. Noh, N. Jeon, Y. Kim, S. Ryu, J. Seo and S. Seok, Science, 2015, 348, 1234-1237.

8 G. Eperon, S. Stranks, C. Menelaou, M. Johnston, L. Herz and H. Snaith, Energy Environ. Sci., 2014, 7, 982-988.

9 W. Yang, B. Park, E. Jung, N. Jeon, Y. Kim, D. Lee, S. Shin, J. Seo, E. Kim, J. Noh and S. Seok, Science, 2017, 356, 13761379.

10 S. Pang, H. Hu, J. Zhang, S. Lv, Y. Yu, F. Wei, T. Qin, H. Xu, Z. Liu and G. Cui, Chem. Mater., 2014, 26, 1485-1491.

11 M. Saliba, T. Matsui, K. Domanski, J. Seo, A. Ummadisingu, S. Zakeeruddin, J. Baena, W. Tress, A. Abate, A. Hagfeldt and M. Grätzel, Science, 2016, 354, 206-209.

12 J. Liu, Y. Shirai, X. Yang, Y. Yue, W. Chen, Y. Wu, A. Islam and L. Han, Adv. Mater., 2015, 27, 4918-4923.

13 N. Pellet, P. Gao, G. Gregori, T. Yang, M. Nazeeruddin, J. Maier and M. Grätzel, Angew. Chem., Int. Ed., 2014, 53, 3151-3157.
14 N. Jeon, J. Noh, W. Yang, Y. Kim, S. Ryu, J. Seo and S. Seok, Nature, 2015, 517, 476-480.

15 J. Wu, X. Xu, Y. Zhao, J. Shi, Y. Xu, Y. Luo, D. Li, H. Wu and Q. Meng, ACS Appl. Mater. Interfaces, 2017, 9, 26937-26947.

16 J. Lee, D. Kim, H. Kim, S. Seo, S. Cho and N. Park, Adv. Energy Mater., 2015, 5, 1501310.

17 X. Xia, W. Wu, H. Li, B. Zheng, Y. Xue, J. Xu, D. Zhang, C. Gao and X. Liu, RSC Adv., 2016, 6, 14792-14798.

18 T. Liu, Y. Zong, Y. Zhou, M. Yang, Z. Li, O. Game, K. Zhu, R. Zhu, Q. Gong and N. Padture, Chem. Mater., 2017, 29, 3246-3250.

19 N. Zhou, Y. Shen, Y. Zhang, Z. Xu, G. Zheng, L. Li, Q. Chen and H. Zhou, Small, 2017, 13, 1700484.

20 Y. Yu, C. Wang, C. Grice, N. Shrestha, J. Chen, D. Zhao, W. Liao, A. Cimaroli, P. Roland, R. Ellingson and Y. Yan, ChemSusChem, 2016, 9, 3288-3297.

21 X. Zhang, G. Ji, D. Xiong, Z. Su, B. Zhao, K. Shen, Y. Yang and X. Gao, RSC Adv., 2018, 8, 987-993.

22 J. Lee and S. Baik, RSC Adv., 2018, 8, 1005-1013.

23 J. Wi, T. Kim, J. Kim, W. Lee, D. Cho, W. Han and Y. Chung, ACS Appl. Mater. Interfaces, 2015, 7, 17425-17432.

$24 \mathrm{~K}$. Torigoe and T. Ono, Enhanced diffusion of boron by oxygen precipitation in heavily boron-doped silicon, $J$. Appl. Phys., 2017, 121, 215103.

25 W. Chen, Q. Luo, X. Deng, J. Zheng, C. Zhang, X. Chen and S. Huang, RSC Adv., 2017, 7, 54068-54077.

26 K. Woo, Y. Kim, W. Yang, K. Kim, I. Kim, Y. Oh, J. Kim and J. Moon, Sci. Rep., 2013, 3, 3069-3076.

27 W. Tress, K. Leo and M. Riede, Sol. Energy Mater. Sol. Cells, 2011, 95, 2981-2986.

28 J. Kim, H. Choi, C. Nahm, C. Kim, J. Kim, W. Lee, S. Kang, B. Lee, T. Hwang, H. Park and B. Park, Appl. Phys. Lett., 2013, 102, 183901.

29 K. Cho, S. Paek, G. Grancini, C. Carmona, P. Gao, Y. Lee and M. Nazeeruddin, Energy Environ. Sci., 2017, 10, 621-627.

30 M. Kim, B. Kim, D. Son, N. Park, H. Jung and M. Cho, Nano Lett., 2016, 16, 5756-5763.

31 O. Ergen, S. Gilbert, T. Pham, S. Turner, M. Tan, M. Worsley and A. Zettl, Nat. Mater., 2017, 16, 522-525.

32 Y. Wu, A. Islam, X. Yang, C. Qin, J. Liu, K. Zhang, W. Peng and L. Han, Energy Environ. Sci., 2014, 7, 2934-2938.

33 F. Shao, L. Xu, Z. Tian, Y. Xie, Y. Wang, P. Sheng, D. Wang and F. Huang, RSC Adv., 2016, 6, 42377-42381.

34 R. Niemann, L. Gouda, J. Hu, S. Tirosh, R. Gottesman, P. Camerona and A. Zabanb, J. Mater. Chem. A, 2017, 4, 17819-17827.

35 T. Zhang, M. Dar, G. Li, F. Xu, N. Guo, M. Grätzel and Y. Zhao, Sci. Adv., 2017, 3, 1700841.

36 J. Zhang, E. Perez, I. Sero, B. Viana and T. Pauporte, J. Mater. Chem. A, 2015, 3, 4909-4915.

37 E. Perez, M. Wußler, F. Santiago, K. Wollny, E. Mankel, T. Mayer, W. Jaegermann and I. Sero, J. Phys. Chem. Lett., 2014, 5, 680-685. 